\title{
URGENSI PENGEMBANGAN KURIKULUM PENDIDIKAN ISLAM BERWAWASAN KEBANGSAAN
}

\author{
Syaiful Anwar \\ Uiniversitas Islam Negeri Raden Intan Lampung
}

Jl. Letkol H. Endro Suratmin, Kota Bandar Lampung, Lampung 35131

E-mail: syaiful.anwar@radenintan.ac.id

\section{Rifda El Fiah}

Uiniversitas Islam Negeri Raden Intan Lampung

Jl. Letkol H. Endro Suratmin, Kota Bandar Lampung, Lampung 35131

E-mail: rifdaelfiah@radenintan.ac.id

\begin{tabular}{c|c|c}
\hline Received: & Revised: & Approved: \\
26/10/2018 & $29 / 11 / 2018$ & $29 / 11 / 2018$ \\
\hline
\end{tabular}

DOI: http://dx.doi.org/10.32332/akademika.v23i2.1246

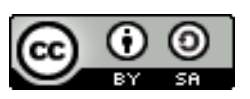

Urgensi Pengembangan Kurikulum Pendidikan Islam Berwawasan Kebangsaan Licensed Under a Creative Commons Attribution-ShareAlike 4.0 International License

\begin{abstract}
Developing students' characters to love the homeland, uphold peace, work productively, respect differences (pluralism), and maintain unity serve as basic framework of the Islamic education. Such characters must always be nurtured and sown on each individual learner through education and teaching with nationalism insight. In accordance with its basic role which is always oriented to the future and the benefit of the people, the writer seeks to discuss the development of a national-minded Islamic education curriculum which is currently very much needed in the framework of giving birth to the next generation with a better quality of understanding, service and nationalism
\end{abstract}


than current generation. The method used in this research was descriptive qualitative method namely library research. The results of data analysis show that the development of nationally-minded Islamic education has quantitative meanings and qualitative meanings. Quantitatively, the development of Islamic-minded Islamic education can be done by increasing the reading references, expanding socialization, making forums, and developing a culture that accommodates national values in Islamic education, quantitatively developing components that need to be developed is strengthening the theoretical foundation and the translation, developing the curriculum, improving the quality of teaching staff, and education, financing and reviving local traditions/culture that do not conflict with the spirit and values of existing Islam.

Keywords: Urgency, Islamic Education Curriculum, and Nationality Insight.

\begin{abstract}
Abstrak
Menumbuh kembangkan karakter peserta didik akan cinta tanah air, menjunjung perdamaian, dan dapat bekerja sama secara produktif, menghargai perbedaan (pluralisme), menjaga persatuan dan kesatuan sebagai kerangka dasar yang sangat penting yang merupakan peran dari pendidikan Islam, sehingga harus selalu dipupuk dan disemai pada setiap pribadi peserta didik melalui pendidikan dan pengajaran yang berwawasan kebangsaan. Sesuai dengan peran dasarnya yang selalu berorentasi ke masa depan dan kemaslahatan umat, maka penulis berupaya membahas tentang pengembangan kurikulum pendidikan Islam berwawasan kebangsaan yang saat ini sangat diperlukan dalam kerangka untuk melahirkan generasi penerus bangsa dengan kualitas pemahaman, jasa dan semangat kebangsaan yang lebih baik dibandingkan dengan generasi sekarang. Metode yang digunakan dalam penelitian ini adalah metode deskriptif kualitatif dengan jenis penelitian yaitu penelitian kepustakaan (library research). Adapun Hasil analisis data bahwa Pengembangan pendidikan Islam berwawasan kebangsaan memiliki makna kuantitatif dan makna kualitatif. Secara kuantitafif pengembangan pendidikan Islam berwawasan kebangasaan dapat dilakukan dengan memperbanyak referensi bacaan, memperluas sosialisasi, membuat forumforum, serta membangan kultur yang mengakomodasi nilai-nilai kebangsaan dalam pendidikan Islam, pengembangan secara kuantitatif yaitu komponenkomponen yang perlu dikembangknan adalah penguatan landasan teori dan penjabarannya, mengembangkan kurikulum, meningkatkan kualitas SDMtenaga pendidik, dan kependidikan, pembiayaan serta menghidupkan tradisi atau budaya lokal yang tidak bertentangan spirit dan nilai-nilai islam yang ada.
\end{abstract}

Kata Kunci: Urgensi, Kurikulum Pendidikan Islam, dan Wawasan Kebangsaan. 


\section{A. Pendahuluan}

Setelah setengah abad lebih mengikat dan menjadi satu bangsa Indonesia, kini rasa persatuan dan kesatuan bangsa mengalami gejala disintegrasi yang cukup memprihatinkan, bahkan berbagai kalangan mengatakan bahwa dewasa ini kecintaan dan kebanggaan kepada bangsa dan tanah air Indonesia semakin memudar, bahkan rasa nasionalisme dikuatirkan bisa lenyap seiring dengan semakin kompleknya kehidupan berbangsa dan bernegara. Terlebih lagi lingkungan strategis kita baik internal dan eksternal perkembangannya semakin cepat dan komplek (dynamic complicity). Pengaruh globalisasi seperti akibat kemajuan dalam bidang telekomunikasi, traveling, transfortasi dan media cetak maupun elektronik telah merambah tata kehidupan masyarakat Indonesia sehingga wawasan kebangsaan masyarakat dapat menurun.

Perubahan tata kehidupan masyarakat pada masa reformasi ini juga menyebabkan penurunan kualitas budi pekerti yang ditandai dengan (1) meningkatnya kekerasan dikalangan remaja (2) penggunaan bahasa dan kata-kata memburuk (3) pengaruh peergrup yang kuat dalam tindak kekekrasan (4) meningkatnya perilaku merusak diri seperti penggunaan narkoba, dan seks bebas (5) semakin kaburnya pedoman moral baik dan buruk (6) menurunnya etos kerja; (7) semakin rendahnya rasa hormat kepada orang tua dan guru; (8) rendahnya rasa tanggung jawab individu dan warga Negara; (9) membudayanya ketidakjujuraan; dan (10) adanya rasa saling curiga dan kebencian diantara sesama. ${ }^{1}$ Lingkungan dan sistem yang cenderung hidomis matrealistis telah menyeret sebagian masyarakat pada sifat ego dan arogan sehingga munculnya demoralisasi. ${ }^{2}$ Sebagai akumulasi maraknya fenomena potologi social tersebut kerisis morallah yang menjadi akar permasalahannya.

Pesatnya perkembangan dan gelombang globalisasi tidak hanya mempengaruhi kultur budaya bangsa, namun juga mempengaruhi wawasan kebangsaan masyarakat yang saat ini mengalami penurunan atau degradasi. Maka dari itu diperlukan adanya upaya sungguhsungguh dan sistematis menanamkan, menumbuh kembangkan dan

${ }^{1}$ Nilawati Tajuddin, Pendidikan Moral Anak Usia Dini Dalam Pandangan Nasikh Ulwan dan Kallbreg. (lampung: LP2M UIN Lampung, 2017).

2 Slueek E.T.A, “Morl Dicriminatif Instrument For The Identification Of Polential Deliguments Al Sehool Entrane Journal of Criminal Law" 51 (1966): 27. 
memelihara wawasan kebangsaan masyarakat melalui sentra-sentra pendidikan informal, nonformal, khususnya lembaga pendidikan formal yang disebut dengan Tri Pusat Pendidikan. Dalam kaitan ini Prof. Dr. Rosdi Eko, M.Sc dalam forum kebangsaan Kota Semarang 2007 di gedung Balai Kota (29/8) seperti dikutip oleh Drs. H. Sigit Sumarhaen Yanto bahwa seluruh sentra/Tri pusat pendidikan hendaknya mengembangkan pola pendidikan inklusivisme bukan eksklusivisme dalam menumbuh kembangkan wawasan kebangsaan.

Wawasan kebangsaan didefinisikan sebagai sudut pandang atau cara memandang yang mengandung kemampuan seseorang atau kelompok orang untuk memahami keberadaan jati dirinya dan tingkah laku sesuai dengan falsafah hidup bangsanya dalam lingkungan internal dan eksternalnya. Hasil pandangan itu merumuskan bahwa negara Indonesia itu merupakan negara kepulauan yang mempunyai kesatuan politik, kesatuan ekonomi, kesatuan sosial budaya, kesatuan sistem pertahanan dan keamanan serta segala macam aspek kehidupan yang serba satu.

Mengingat wawasan kebangsaan saat ini mengalami degradasi/ penurunan yang sedemikian parah, maka berbagai upaya lembaga pendidikan harus dilakukan, kalau tidak maka tinggal menunggu kehancurannya yang tentu tidak kita harapkan.

Dari uraian diatas jelaslah bahwa misi dari pendidikan itu adalah membuat manusia menjadi manusia. Artinya pendidikan harus mengarahkan seseorang individu yang memiliki karakter positif dengan ciri insan yang sadarakan dirinya dan sadar lingkungnnya.

Pendidikan Islam sebagai suatu sistem dari pendidikan nasional memegang peranan penting dan strategis dalam membangun visi kebangsaan. Akan tetapi dalam kenyataannya diakui atau tidak justru belakangan ini terkesan bahwa umat banyak terjebak pada pengembangan faham anti kebangsaan dan cenderung mengembangkan ajaran dan paham radikal yang menganggap Islam anti (bertentangan) dengan ideologi kebangsaan (Pancasila dan UUD 45) dengan segala argumen dalil dan hadits. Oleh karena itu pendidikan Islam harus mampu merespon problematik ajaran dan penafsiran keagamaan yang selaras dengan Islam Rahmatan lil alamin dan Islam washatiyah, Islam yang 
membawa kedamaian, rahmat dan kasih sayang antar sesama. Untuk itu pengembangan kurikulum pendidikan Islam berwawasan kebangsaan menjadi penting untuk dikaji dan dirumuskan secara cermat dan mendalam, karena kurikulum merupakan inti dari proses pendidikan. Kurikulum sangat menentukan proses dan hasil suatu sistem pendidikan. Kurikulum juga bisa berfungsi sebagai media untuk mencapai tujuan sekaligus sebagai pedoman dalam pelaksanaan pengajaran pada semua jenis dan semua tingkat pendidikan ${ }^{3}$

Dalam pandangan dunia pendidikan ${ }^{4}$, keberhasilan dunia pendidikan sangat tergantung pada program kurikulum karena kurikulum pada dasarnya berfungsi untuk menyediakan program pendidikan yang relevan bagi pencapaian sasaran pendidikan akhir. Dengan kata lain fungsi kurikulum adalah "shaping the individual selver, ie determining what man become". Untuk mencapai hal itu kurikulum berfungsi menyiapkan dan membentuk peserta didik agar dapat menjadi manusia dan sasaran akhir program pendidikan. Program kurikulum pemdidikan harus diorientasikan dan disesuaikan dengan kebutuhan masa kini dan masa yang akan datang. ${ }^{5}$ Dengan demikian kurikulum memiliki posisi strategis karena secara umum kurikulum merupakan deskripsi dari visi, misi, dan tujuan pendidikan sebuah bangsa, hal ini sekaligus memposisikan kurikulum sebagai senteral muatan-muatan nilai yang akan ditranspormasikan kepada peserta didik.

Arah dan tujuan kurikulum pendidikan juga tidak terlepas dari sebuah dinamika kemajuan dan perubahan suatu bangsa yang bersangkutan karena itu kurikulum pendidikan harus memiliki sifat dan daya kelenturan (fleksibelitas) dan fotoristik yang mampu beradaptasi dengan kemajuan dan masa depan suatu bangsa.

Atas dasar pertimbangan ini, maka pengembangan kurikulum pendidikan Islam menjadi salah satu tugas pokok pemerintah untuk mengatur dan mengembangkan pendidikan. Demikian juga halnya dengan peran tokoh maupun pemerhati pendidikan agar mengikuti setiap episode dari perubahan sosial, karena semua itu menjadi bahan

\footnotetext{
${ }^{3}$ Konsep dan Model Pengembangan Kurikulum (Bandung: Remaja Karya, 2011), 29.

${ }^{4}$ Ade Imelda dan Frimayanti, "IMPLEMENTASI PENDIDIKAN NILAI DALAM PENDIDIKAN AGAMA ISLAM" 6 (November 2015).

5 Mujibur Rahman, "Problamatik Kurikulum Pendidikan Islam" VIII (Januari 2015): 3 .
} 
pertimbangan dalam mendesain seta mengembangkan kurikulum. Selain itu partisifasi aktif masyarakat juga sangat diharapkan untuk memberikan sumbangan pemikiran dalam merespon setiap perubahan. ${ }^{6}$

Sebelumnya terdapat beberapa penelitian yang mengkaji pendidikan Islam, Pertama Problem Keilmuan Pendidikan Agama Islam oleh M. Saekhan Muchith ${ }^{7}$ dengan hasil kajian yaitu Problem keilmuan berupa epistimologi atau dikotomi di dalam lingkungan pendidikan Islam atau lembaga pendidikan Islam semacam STAIN, IAIN dan UIN merupakan problem yang selain dikatakan problem keilmuan juga dapat dikatakan sebagai problem kultural. Artinya, problem tersebut tidak mungkin dihilangkan karena ini menyangkut karakteristik kelembagaan dan keilmuan. Meskipun demikian, problem dikotomi jangan sampai menjadi perdebatan terlalu panjang sehingga Islam tidak optimal menjalankan peran dan fungsinya sebagai agama rahmatan l'alamiin. Kedua, Memahami Pendidikan Islam oleh Fauti Subhan ${ }^{8}$ Secara kajian, di-mensi teoritis dengan aplikatif pendidikan Islam dapat dibahas sendiri-sendiri, tetapi secara praktis, kedua dimensi tersebut tidak bisa lepas satu sama lain. Pada prinsipnya, persoalan pendidikan Islam tidak dapat dilepaskan dari beragam per-soalan lainnya. Pendidikan Islam selalu terkait dengan berbagai elemen kehi-dupan, terutama manusia. Melalui pendidikan Islam manusia dapat tumbuh dan berkembang dengan baik. Sebaliknya, manusia (Muslim) juga menjadi aktor dari maju atau mundurnya pendidikan Islam. Antara umat Islam dan pendidikan Is-lam merupakan dua hal yang dapat diibaratkan seperti sekeping uang, yakni terdiri dari dua sisi yang berbeda tetapi tidak terpisah antara satu dengan lainnya. Ketiga, tujuan pendidikan islam oleh imam syafe' $i^{9}$ dengan hasil kajian yaitu Menurut Jalaluddin tujuan pendidikan Islam harus dirumuskan dari nilai-nilai filosofis yang terkandung dalam filsafat pendidikan Islam. Tujuan pendidikan Islam menurutnya identik dengan tujuan Islam itu sendiri. Menurut Abdurrahman Saleh Abdullah, ada tiga Putura.," t.t.

6 "Samsul Bahri Pengembangan Kurikulum Dasar dan Tujuannya Jurnal Islam

7 M Saekan Muchith, "Problem Keilmuan Pendidikan Agama Islam," JURNAL PENELITIAN 9, no. 2 (1 Agustus 2015): 389, https:/ / doi.org/10.21043/jupe.v9i2.1327.

${ }^{8}$ Fauti Subhan, "Memahami Pendidikan Islam," Nadwa 7, no. 1 (20 April 2013): 141, https://doi.org/10.21580/nw.2013.7.1.547.

9 Imam Syafe'I, “TUJUAN PENDIDIKAN ISLAM," Jurnal Pendidikan Islam 6 (2015): 16. 
tujuan utama pendidikan Islam, yaitu "tujuan fisik (ahdaf al-jismiyyah), penyebab spiritual (ahdaf a Karena itu, pendidikan mempunyalruhiyyah), dan tujuan mental (ahdaf al- 'aqliyyah). Perbedaan dengan artikel sebelumnya, artikel ini mencoba mendeskripsikan urgensi pengembangan kurikulum pendidikan Islam dalam kontek menumbuh kembangkan, memelihara dan menjaga wawasan kebangsaan Nasional, agar tetap berdiri kokoh dengan disemangati nilai-nilai dan moral Islam. Sehingga Islam dan semangat kebangsaan menjadi suatu hal yang tidak dapat dipisahkan laksana dua sisi mata uang.

\section{B. Hakikat Pendidikan Islam Berwawasan Kebangsaan}

Kata wawasan berasal dari bahasa jawa yaitu wawas yang artinya memandang atau melihat, jadi kata wawasan dapat diartikan cara melihat atau cara pandang, sementara itu kosakata kebangsaan berasal dari kata "bangsa" yang mendapat awalan ke, dan akhiran an. Dalam Encyclopedia poritanica,kebangsaan (nasionalisme)diartikan sebagai keadaan jiwa dimana individu merasa bahwa setiap orang memiliki kesetiaan dan keduniaan (sekuler) tertinggi kepada Negara kebangsaan ${ }^{10}$ yang selanjutnya dalam Internasional Ennyclopedia of the social seiesies, dikemukakan bahwa nasionalisme/kebangsaan adalah suatu ikatan politik yang mengikat kesatuan masyarakat modern, dan memberi pengabsahan terhadap klaim (tuntutan) kekuasaan. ${ }^{11}$ Sedangkan L Stoddard menggolongkan nasionalisme/kebangsaan sebagai suatu keadaan jiwa dan suatu kepercayaan dianut adalah sejumlah besar manusia perseorangan sehingga mereka membentuk,suatu kebangsaan ${ }^{12}$ Nasionalisme adalah rasa kebersamaan segolongan sebagai suatu bangsa.

Secara sederhana, wawasan kebangsaan dapat berarti 'keragaman budaya' ${ }^{13}$ istilah wawasan kebangsaan tersebut dibentuk dari kata wawas yang berarti pandangan; atau cara pandang, dan kebangsaan yang berarti

10 "Encyclopedia britanica the university (cicagi:851).," t.t., 851.

${ }^{11}$ David L Sill (ed), "new York international Encyclopedia of the social scence the Mee Millon," 1972.

${ }^{12}$ Stoddard, L, .. dunia BMM islam (Jakarta: gunung agung, 1964).

${ }_{13}$ Scott Lash Dan Mike Featherstone (Ed.), Recognition And Difference: Politics, Identity, Multiculture (Londen: Sage Publication, 2002), 2. 
cinta pada tanah air, persatuan dan kesatuan. ${ }^{14}$ Kultur atau budaya merupakan ciri-ciri dari tingkahlaku manusia yang dipelajari, tidak diturunkan secara genetis dan bersifat khusus, sehingga kultur pada masyarakat tertentu bisa berbeda dengan kultur masyarakat lainnya. ${ }^{15}$

Dari uraian diatas dapat disimpulkan bahwa, wawasan kebangsaan adalah cara pandang suatu bangsa terhadap prinsip-prinsip dasar kebangsaan yang menjadi ciri atau identitas kepribadian bangsa tersebut. Sehingga dengan berpedoman seperti cara pandang yang menjadi prinsip dasar kebangsaan itu, maka bangsa tersebut memiliki sikap dan jati diri sesuai dengan nilai-nilai dasar yang diakuinya.

Bangsa Indonesia memiliki cara pandang untuk melangkah kedepan dalam mencapai tujuan nasional.Wawasankebangsaan Indonesia dengan demikian merupakan suatu pandang atau cara pandang yang memuliakan sikap dan kepribadian bangsa Indonesia yang memiliki rasa cinta pada tanah air, menjunjung tinggi rasa persatuan dan kesatuan, memiliki rasa kebersamaan sebagai bangsa untuk membangun Indonesia menuju masadepan yang lebih baik, di tengah persaingan dunia dan globalistik, tanpa harus kehilangan adat budaya dan nilai-nilai dasar pancasila yang telah kita miliki. Wawasan kebangsaan meliputi wawasan kedalam dan wawasan keluar. Wawasan kedalam artinya memandang kepada diri bangsa Indonesia sendiri yang memiliki wilayah tanah air yang luas, jumlah penduduk yang banyak, keanekaragaman budaya, adat istiadat dan lain-lain, harus dilakukan dalam suatu pandangan yang mendasarkan kepada kepentingan bersama sebagai bangsa.

Dalam konteks pemahaman Islam, keberagaman juga terjadi. Keberagaman tersebut pada gilirannya memunculkan pola-pola artikulasi keberagaman, yang menurut Azra, sebagaimana dikutip Muhaimin, dikelompokkan dalam tiga tipologi, yaitu (1) Substansialisme yang lebih mementingkan substansi atau isi dari pada label atau simbolsimbol eksplinsip;(2) Formalisme/legalisme yang cenderung sangat literal atau ketaatan formal dan hukum agama, diekspresikan dalam bentuk sangat lahiriyah semacam simbol keagamaan;(3) Spiritualisme

${ }^{14}$ M. Amin Abdulah, Pendidikan Agama Era Multikultural Religius ((Jakarta: Psap Muhammaddiyah, 2005), 13.

${ }_{15}$ M. Ainul Yaqin, , Pendidikan Multicultural (Cross-Cultural Understanding Untuk Demokrasi danKeadilan) (Yogyakarta: Pilar Media, 2005), 9. 
yang lebih menekankan kepada pengembangan sikap batiniah, melalui keikutsertaan dalam kelompok spiritual mistik, tasawuf, tarekat bahkan kelompok kultus. ${ }^{16}$

Berangkat dari pemikiran di atas, maka sudah seharusnya nilainilai kebangsaan dapat terintegrasi secara jelas dalam agenda pendidikan Islam. Adapunpendidikan Islam,dalam pengertian yang bersifat normatif merupakan suatu proses spiritual, akhlak,intelektual dan sosial untuk membimbing manusia sekaligus memberikan kepada mereka nilai-nilai, prinsip-prinsip dan teladan ideal dalam kehidupan, dengan tujuan untuk memperoleh kebahagiaan hidup dunia dan akhirat. ${ }^{17}$

pendidikan Islam wawasan kebangsaan pada hakikatnya adalah pendidikan yang menempatkan isu kebangsaan sebagai salah satu visi pendidikan dengan karakter utama yang bersifat inklusif,egaliter dan humanis, namun tetap kukuh pada nilai-nilai spiritual dan ketuhanan yang berdasarkan Al-quran dan Al-sunnah.

Wujud suatu Negara jika didalamnya terbentuk sebuah masyarakat Qurani, maka itupun sudah merupakan tanda-tanda Negara Islam $^{18}$ ketiadaan penjelasan resmi tentang Negara memungkinkan Islam untuk mengikuti kemajuan zaman dan menyesuaikan diri terhadap kondisi dan lingkungan, tempat ia tumbuh dan berkembang.

Pendidikan Islam berwawasan kebangsaan dalam artikel ini mengacu pada konsepsi dalam rumusan pendidikan Nasional yang menjelaskan yaitu dapat ditinjau secara konsepsional dan operasional. Secara konsepsional pendidikan berwawasan kebangsaan mencakup ciriciri dan pengertian sebagai berikut:

1. Upaya sistematis dan kontinu yang diselenggarakan oleh lembaga pendidikan untuk menyiapkan peserta didik menjadi warga Negara yang baik dan bertanggung jawab dalam peranannya pada saat sekarang dan masa yang akan datang.

2. Upaya pengembangan, peningkatan, dan pemeliharaan pemahaman, sikap dan tingkah laku siswa yang menonjolkan

${ }^{16}$ Muhaimin, Arah Baru Pengembangan Pendidikan Islam (Bandung: Tarsito, 2003), 56.

${ }_{17}$ Hasan Langgulung, Asas-Asas Pendidikan Islam (Jakarta: Pustaka Al-Husna, 1963), 62.

18 Asghar Ali Enginer, "Devolusi Negara Islam, Teerj. Imam Muttaqin" (Yogyakarta: Pustaka Pelajar, 2000), 59. 
persaudaraan, penghargaan positif, cinta damai, demokrasi dan keterbukaan yang wajar dalam berinteraksi sosial dengan sesama warga Negara Kesatuan Republik Indonesia atau dengan sesama warga dunia.

3. Keseluruhan upaya pendidikan Islam untuk membentuk peserta didik menjadi warganegara yang baik dan bertanggung jawab melalui upaya bimbingan, pengajaran, pembiasaan, keteladanan, dan latihan sehingga dapat menjalankan peranannya pada saat sekarang dan masa yang akan datang. ${ }^{19}$

Secara oprasional, pendidikan Islam berwawasan kebangsaan adalah layanan bimbingan pengajaran atau pelatihan untuk meningkatkan paham, rasa, dan semangat kebangsaan yang baik pada siswa, yang ditunjukan dengan mengutamakan tingkahlaku bersaudara, demokratis, saling menerima dan menghargai, serta saling menolong dalam berinteraksi social dengan sesama warga Indonesia.

Adapun tujuan dari pendidikan Islam berwawasan kebangsaan terlebih dahulu kita harus menyadari secara seksama, bahwa kita hidup di negara yang relatif wawasan kebangsaan dengan berbagai macam kelompok suku, budaya, ras serta Agama dan keyakinan yang harus dimaknai secara positif atas keragaman tersebut. Indonesia sebagai suatu Negara yang berdasarkan pancasila telah disepakati oleh faunding father kita. Pendidikan sebagai alat untuk membungkus ataupun mewadahi cara pandang yang berbeda dalam memahami sebuah persoalan kemasyarakatan harus mampu menjadi tali ikat untuk menumbuhkan semangat persatuan dan rasa kebangsaan, bahwa kita semua adalah saudara sebangsa dan setanah air, jikalau ada satu diantara kita yang disakiti atau merasa tersakiti, atau tanah air kita ada yang mencuri secuil kepentingan, maka penting bagi kita untuk tidak membiarkan.

Maka dari itu, pentinglah kita untuk memahami dan mengimplementasikan dari pada tujuan pendidikan yang berwawasan kebangsaan dalam semua lini jenjang pendidikan baik formal, non formal, maupun in-formal.

Tujuan dari pendidikan berwawasan kebangsaan meliputi, antara lain sebagai berikut:

${ }^{19}$ Departemen Pendidikan Nasional, Panduan Pelaksanaan, t.t., 7-8. 
a. Meningkatkan pengertian, pemahaman, dan persepsi yang tepat tentang persatuan dan kesatuan antar sesame warga NKRI.

b. Menanamkan jiwa kepemimpinan dan tanggung jawab sebagai persatuan bangsa Indonesia

c. Mengembangkan kepekaan sosial, solidaritas, toleransi, dan saling mengenal serta saling menolong antar sesame warga NKRI walaupun berbeda latar belakang.

d. Meningkatkan kemampuan dan keterampilan siswa dalam mengelola konflik antar-pribadi dan antar kelompok. ${ }^{20}$

Adapun tujuan dari pendidikan berwawasan kebangsaan tidak berbeda dari visi dan misi pendidikan nasional, yaitu menjadikan peserta didik secara aktif untuk mengembangkan potensi dirinya, memiliki kekuatan spiritual keagamaan, pengendalian diri, keperibadian, kecerdasan, akhlak mulia, serta keterampilan yang diperlukan dirinya, masyarakat, bangsa dan Negara. ${ }^{21}$

Pendidikan berwawasan kebangsaan berorientasi terhadap; (1) paham kebangsaan, (2) rasa kebangsaan, (3) semangat kebangsaan. Paham kebangsaan merupakan refleksi dari kesadaran individu akan kebhinneka tunggalikaan masyarakat Indonesia. Refleksi kesadaran tersebut dijadikan pedoman berperilaku dalam kehidupan berbangsa dan bermasyarakat yang majemuk.

Jadi, pendidikan Islam berwawasan Kebangsaan adalah, suatu cara pandang sistem pendidikan Islam yang mempunyai nilainilai, visi sosial kemasyarakatan yang dilandaskan pada ajaran Islam sarana integrasi bangsa, berarti rasa kesatuan yang tumbuh dalam hati sekelompok manusia berdasarkan cita-cita yang sama dalam satu ikatan organisasi kenegaraan Indonesia. Persatuan indonesia adalah proses untuk menuju terwujudnya nasionalisme Indonesia yang religius.

\section{Faktor Pentingnya Pendidikan Islam Berwawasan Kebangsaan}

Dari berbagai kalangan mengatakan bahwa dewasa ini kecintaan dan kebanggaan kepada bangsa dan tanah air indonesia semakin memudar,

20 “Departemen Pendidikan Nasiaonal, Panduan Pelaksanaan, Hal. 8-9" (t.t.), 8-9.

${ }^{21}$ Undang-Undamg System Pendidikan Nasional, Cet. III (Yogyakarta: Pustaka Pelajar, 2009), 3. 
bahkan rasa nasionalisme dikhawatirkan bisa lenyap seiring dengan semakin kompleknya kehidupan berbangsa dan bernegara. Terlebih lagi lingkungaan strategis kita baik internal dan eksternal perkembanganya semakin cepat dan komplek (DyenamicCompecity). Pengaruh globalisasi seperti akibat kemajuan dalam bidang telekomunikasi, traveling, transportasi dan media cetak maupun elektronik telah mengubah tata kehidupan masyarakat Indonesia sehingga wawasan kebangsaan masyarakat dapat menurun.

Pesatnya perkembangan globalisasi tidak hanya mempengaruhi kultur budaya bangsa,namun juga mempengaruhi wawasan kebangsaan masyarakat yang saat ini mulai mengalami penurunan atau degradasi. Maka perlu adanya upaya menanamkan,menumbuh kembangkan dan memelihara wawasan kebangsaan masyarakat melalui sentra-sentra pendidikan seperti sentra keluarga, masyarakat dan sekolah, yang disebut pula sebagai trisentra pendidikan(tiga pusat pendidikan)." Seluruh sentra tersebut dikembangkan inklusivisme bukan ekslusivisme dimulai dari keluarga, masyarakat (Society maupun Community) dan sekolah", tutur Prof.Dr.SardiEko Siswoyo,MSc dalam forum kebangsaan kota Semarang 2007 digedung balai kota, Rabu(29/8).

Wawasan kebangsaan didefinisikan sebagai sudut pandang atau cara memandang yang mengandung kemampuan seseorang atau kelompok orang untuk memahami keberadaan jati dirinya sebagai suatu bangsa,juga dalam memandang dirinya dan tingkah laku sesuai falsafah hidup bangsanya dalam lingkungan internal dan lingkungan eksternalnya. Hasil pandangan itu merumuskan bahwa Negara Indonesia merupakan Negara kepulauan yang mempunyai kesatuan politik, kesatuan ekonomi, kesatuan sosial budaya, kesatuan sistem pertahanan dan keamanan, serta segala macam aspek kehidupan yang serba satu.

Dalam konteks hal diatas maka peran pendidikan Islam sesungguhnya sangat penting dan relevan untuk menumbuh kembangkan wawasan kebangsaan pada satuan dan jenjang pendidikan Islam mulai dari sekolah dasar, menengah, atas, bahkan pada perguruan tinggi, hal ini megingat mayoritas penduduk Indonesia $87 \%$ dari 250 juta jiwa adalah muslim disamping itu ajaran Islam itu sendiri melalui Kitab Suci AlQur'an dan Hadits Nabi banyak memberikan petunjuk dan ajaran berupa 
nilai-nilai kesatuan, kebangsaan, seperti: cinta pada tanah air, persatuan, demokrasi, keadilan, menghargai perbedaan dan lain-lain.

Gagasan yang berupaya mengembangkan pendidikan Islam melalui penataan dan pengembangan keperibadian yang bernuansa wawasan kebangsaan sudah mulai banyak dirancang dan dirumuskan dalam beberapa dekade belakangan ini tidak sedikit pula ideide bermunculan terkait wawasan kebangsaan yang teraktualisasi dalam wacana pendidikan Islam, akan tetapi dilihat dari proses pengembangan serta aspek implementasinya masih belum berjalan sesuai harapan, pelaksanaan pendidikan Islam berwawasan kebangsaan ini masihdihadapkan pada berbagai macam persoalan, sebagai wacana yang relatif baru, hal ini tentu saja dapat dipahami akan tetapi apabila dikaitkan dengan yang terjadi dan berbagai persoalan yang ada fenomena dilapangan, kebutuhan akan implementasi yang tepat danterarah merupakan hal yang mendasar untuk dilakukan.

Persoalan-persoalan yang muncul setidaknya dapat dilihat dari dua aspek yakni pertama, aspek kuantitatif, pendidikan Islam berwawasan kebangsaan masih belum tersosialisasikan dengan baik dan belum berpengaruh luas terhadap masyarakat, terutama dilingkungan pendidikan, walaupun ditingkat perguruan tinggin (PTAI)karena wawasan kebangsaan ini sudah cukup mendapat tempat, namun ditingkat sekala seluruh (Mencegah) terkhususnya yang berada didaerah, belum termasukdan tersosialisasikan maupun persatuan sepirit dan nilai-nilai kebangsaan belum terumus dan tersosialisasikan secara luas dan intens. Begitupun dengan pemahaman masyarakat terkait pentingnya wawasan kebangsaan secara umum dapat dilihatmasih sangat kurang dan sempit. Kedua aspek kualitatif. baik dari sisi konsep maupun implementasi masih banyak bagian yang perlu dibenahi dan dikembangkan. Secara konsep pendidikan Islam berwawasan kebangsaan kurang tersistematisasi dengan baik, terutama untuk dijadikn dasar dalam persamaannya di lapangan inperensi hasil pemikiran yang secara rinci dan sistematis menjelaskan bentuk-bentuk implementasi pendidikan Islam berwawasan kebangsaan sehingga berdampak pada usahausaha praktis yang dilakukan. Begitu juga dalam masa pembelajaran terutama padaseluruhtingkat menganggap wawasan kebangsaan belum terintegrasi secara jelas didalam kurikulum, baik sebagai materi sisipan, 
kondisi ini ditambah pula dengan ketersediaan sumberdaya manusia (SDM) guru pendidik yang sebagian besar belum memahami dengan baik mengenai konsep wawasan kebangsaan dan keislaman yang terfitas sehingga pada proses implamalisasi dalam pembelajaran. belum berjalan sebagaimana diharapkan. ${ }^{22}$

Mencermati phenomena seperti yang telah dipaparkan diatas, maka upaya pengembangan kurikulum pendidikan Islam berwawasan kebangsaan sangat perlu dilakukan untuk lebih optimal mensosialisasikan dan melaksanakan pendidikan Islam bercorak wawasan kebangsaan dengan segala dinamikanya.

\section{Upaya Pengembangan Kurikulum Pendidikan Islam Berwawasan Kebangsaan}

Mencermati dinamika kehidupan kebangsaan Indonesia saat ini yang dinilai berbagai kalangan menurun kualitas rasa persatuan dan kesatuan bangsa dan mengalami gejala disintegrasi yang cukup memprihatinkan di satu sisi, dan disisi lain pemahaman ke Islaman umat dalam bentuk wawasan kebangsaan itu sendiri, lebih-lebih dikaitkan dengan Islam atau konsep Islam tentang kebangsaan saat inipun terjadi polarisasi pemikiran, polarisasi itu menampakkan tiga kutub pemikiran besar yaitu Islam dan kebangsaan itu dimaknai suatu hal yang harmonis dan saling melengkapi dan tidak memprtantangkan keduanya, momen justru memberikan pengayaan dan penguatan terhadap konsep-konsep yang melingkari konsep kebangsaan itu sendiri, seperti konsep cinta tanah air, persatuan dan kesatuan, gotong royong, demokrasi, keadilan, kerukunan, ekomomi, budaya dan sebagainya. Konsep-konsep trsebut dipandang memiliki rekvansi yang kuat terhadap ajaran Islam secara makro. Oleh karena itu dalam pemikiran ini Islam ditempatkansebagai ajaran dan teori-teori.

Kemanusiaan yang harmonis, dan mampu menjawab dinamika perubahan dan kemajuan yang ada tanpa mengubah paham budaya ke Indonesiaan yang sudah berkembang berabad-abad lamanya yang kemudian direformasikan dalam format empat filar NKRI yaitu Pancasila, UUN 1945 Pembukaan dan cinta tanah air Indonesia.

${ }^{22}$ Muhammad Fathurahman, "Pendidikan Islam Mesti Cultural, Mengutif dari Artikel Nur Effendi Pendidik 06@ Yahoo.Co.Id," t.t. 
Pandangan-pandangan ini kemudian mencoba melakukan reorentasi kembali tehadap pemahaman idiologi bangsa yang telah diformasi dalam empat pilar kebangsaan tersebut sesuai dengan prinsipprinsip Islam yang benar (Normatif). Dalam batas-batas tertentu pemikiran yang kedua ini sesungguhnya sejalan dengan pemikiran yang pertama, bedanyanya pemikiran yang kedua ini mencoba melakukan kritisi terhadap paktrin idiologi kebangsaan hari ini sudah mulai mengalami distorsi, dan penyimpangan-penyimpangan yang signifikan dari konsep dasar awal yang telah disepakati akan rasa telah pendiri bangsa (Fanding Fatner). Dengan kata lain idiologi kebangsaan saat ini mulai kehilangan jati yaitu hilang dari bentuk (Rel) ruh ke Islaman yang benar.

Sebaliknya bentuk pemikiran ketiga cenderung menggunakan pendekatan keislaman yang radikal dalam makna bahwa segala sesuatu produk pemikiran dan budaya haruslah sejalan dan sesuai dengan pemahaman keislaman yang haffah, dalam bentuk tatanan kehidupan kebangsaan itu harus sesuai dengan cinta dan semangat Islam (AlQur'an dan Al-Hadits) dalam arti yang normatif, oleh karena itu bukan sebaliknyayaitu Islam menyesuaikan dengan tataran budaya kebangsaan. Sebagaimana kita ketahui bahwa tatanan dan idiologi kebangsaan itu tumbuh dari tradisi-tradisi moyang kita dahulu dan tradisi-tradisi Barat yang menganggap paham keagamaan tidak boleh masuk dalam ranah publik, sebaliknya agama dianggap wilayah pripasi (Pribadi), paham ini kemudian disebut dengan skularisasi agama artinya agama harus terpisah dengan kehidupan dunia. Daripemikiran ini menginginkan adanya pembaharuan dan bahkan pergantian konsep-konsep yang jelasjelas bertentangan dengan nilai-nilai dan tradisi islam misalnya konsep demokrasi di ganti dengan konsep khilaffah, klonologi kapitalis diganti dengan konsep ekonomi syari'ah, budaya syirihk diganti dengan budaya syar'i(Islami), sebagai contoh issu Islam nusantara yang kemudian ramaidibicarakan (Viral)dalam wacana publik, sehingga menolak dengan mengatakan bahwa "Islam nusantara itu tidak ada yang ada Islam di nusantara" demikian juga kasus pembubaran ormasIslam HTI yang bermaksud merubah tatanandemokrasi pemerintah kepada konsep khilffah yang kemudian menimbulkan kontropersial dalam wacana public Islam dan paham kebangsaan" dan isu-isu lainnya. 
Dari tiga kutub pemikiran yang telah dijelaskan diatas, poin penting yang ingin disampaikan disini yaitu berupa urgensi pembahasan tentang Islam dan wawasan kebangsaan ini masuk dalam wacana pembahasan pendidikan Islam di Indonesia dan di impementasikan kedalam rumusan kurikuilum pembelajaran dikelas pada masing-masing lembaga pendidikan Islam di Indonesia saat ini, agar bangsa ini tetap eksis, tetap kuat, dalam menjalani prona kehidupan yang kompeks, dan selalu berkembang. Bukan sebaliknya, bangsa yang besar dan dengan jumlah populasi muslimterbesar didunia ini justru menajadi pecah, berantakan, bubar, bahkan hilang dari peredaran peradaban dunia tentu saja hal tersebut tidak kita inginkan.

Adapun rumusan kurikulim wawasan kebagnsaan perspektif Islam dimaksudkandisini yaitu sebuah konsep yang mengacu pada rumusan wawasan kebangsan yang ada, namun dimaknai dan dikuatkan dengan konsepsi pemahaman ajaran praktis keislaman agar hal tersebut menjadi lebih mendalam dan berbekas dalam sebuah keperibadian peserta didik yang harmonis, dinamis dan produktif.

Adapun konsep wawasan kebangsaan tersebut mengacu pada tiga hal yaitu paham kebangsaan, rasa kebangsaan, dan semangat kebangsaan.

Pertama: paham kebangsaan berorientasi pada cara berfikir, yang secara operasional merujuk pada nilai-nilai dan norma kehidupan bermasyarakat dan berbangsa, dilandasi oleh pemahaman yang mendalam akan pandangan hidup, latar belakang masalah, kondisi geografis, kesenian dan bahasa. Aspek-aspeknya ditemukan pada hakhak asasi manusia dan moral dasar Negara modern dalam berbangsa yang meliputi dimensi kebenaran, kesamaan dan keadilan, kedamaian kesetiakawanan, penghormatan pada manusia, integritas, akuntabilitas, kejujuran, penerimaan/penghargaan kebhenikaan, kebebasan dan tanggung jawab.

Kedua: rasa kebangsaan berorientasi pada sikap yang ditanamkan melalui kebiasaan merespon terhadap kejadian atau peristiwa yang terkait pada kehidupan bermasyarakat dan berbangsa diantaranya: penerimaan dan penghargaan atas perbedaan-perbedaan keadaan diri, asal usul keturunan, dan suku bangsa yang mengekspresikan sebagai 
bangsa Indonesia. Aspek-aspeknya menekankan pada nilai perdamaian, patriotism dan nasionalisme yang didalamnya meliputi cinta keharuan dan rasa iba, harmonis, toleransi, nilai simbolik persatuan dan kesatuan bangsa (Bendera Merah Putih, Bahasa Indonesia, Lambing Negara, Lagu IndonesiaRaya) peduli dan berbagi, interdependensi, pengenalan jiwa orang lain, dan rasa berterima kasih.

Ketiga:semangat kebangsaan berorientasi pada perilaku yang merujuk pada dinamika perilaku yang aktraktif dalam perbuatan senasib sepenanggungan, tenggang rasa, aling menghormati, sanggup berkompetisi secara sehat dan menunjukkan kebangsaan sebagai bangsa Indonesia. Aspek-aspeknya menekankan pada nilai demokrasi yang didalamnya meliputi penghormatan pada hokum, kebebasan yang bertanggung jawab, persamaan, disiplin diri, kewarganegaraan yang aktif dan bertanggung jawab, keterbukaan, berfikir kritis, dan solidaritas. ${ }^{23}$ Adapun aspek dimensi dan indikator wawasan kebangsaan dimaksud yaitu sebagai berikut

Dari gambaran diskrepsi muatan wawasan kebangsaan tersebut maka tugas selanjutnya menjabarkannya kedalam rumusan keislaman yang praktis, artinya aspek dimensi dan indikator wawasan kebangsaan yang ada tersebut dibahas dan dipormulasikan kedalam bahasa agama. sehingga mudah dipahami, dimengerti dan dilaksanakan dalam kehidupan sehari-hari oleh setiap peserta didik dilembaga-lembaga pendidikan islam dengan melakukan upaya pengembangan kurikulum pendidikan Islam berwawasan kebangsaan tersebut maka akan dapat berpengaruh pada sikap kebangsaan warga bangsa/masyarakat/peserta didik yang kondusif yaitu kehidupan kebangsaan yang inklusif, inovatif, dan produktif yang disinari dengan nilai-nilai keislaman yang kaffah dan washotiah.

\section{E. Kesimpulan}

Dari uraian yang telah dipaparkan mengenai pengembangan kurikulum pendidikan Islam berwawasan kebangsaan diatas maka dapat disimpulkan bahwa pada dasarnya pendidikan islam berwawasan

${ }^{23}$ Departemen Pendidikan Nasional Doirektorat Jenderal Pendidikan Dasar dan Menengah DirektoratPembinaan Menengah, Pertama Panduan Pelaksanaan Pendidikan Berwawasan Kebangsaan, 2009, 31-35. 
kebangsaan merupakan pendidikan yang menempatkan isu wawasan kebangsaan sebagai salah satu visi pendidikan islam dengan karakter utama bersifat universal, kaffah, inklusif, egaliter, dan humanis namun tetap kokoh memegang teguh tradisi dan nilai-nilai spiritual dan ketuhanan yang berlandaskan Al Qur'an dan Nabi SAW.

Pendidikan Islam berwawasan kebangsaan setidaknya memiliki landasan yang kuat dan jelas baik ditinjau dari aspek landasan (Ideal) maupun landasan empiris, serta mempunyai prinsip dan karakteristik tertentu yaitu: cinta tanah air, menjunjung perdamaian, bekerjasama secara produktif, menghargai perbedaan, menjaga persatuan dan kesatuan bangsa. Nilai-nilai tersebut haruslah tertanamkan pada peserta didik sejak dini melalui proses pendidikan berwawasan kebangsaan.

Pengembangan pendidikan Islam berwawasan kebangsaan, setidaknya memiliki 2 makna yaitu makna kuantitatif dan makna kualitatif. Secara kuantitafif pengembangan pendidikan Islam berwawasan kebangasaan dapat dilakukan dengan memperbanyak referensi bacaan, memperluas sosialisasi, membuat forum-forum, serta membangan kultur yang mengakomodasi nilai-nilai kebangsaan dalam pendidikan Islam, adapun pengembangan secara kuantitatif yaitu komponen-komponen yang perlu dikembangknan adalah penguatan landasan teori dan penjabarannya, mengembangkan kurikulum, meningkatkan kualitas SDMtenaga pendidik, dan kependidikan, pembiayaan serta menghidupkan tradisi/budaya lokal yang tidak bertentangan spirit dan nilai-nilai islam yang ada. Dengan demikian pengembangan pendidikan Islam berwawasan kebangasaan melalui pengembangan kurikulum yang ada pada setiap satuan lembaga pendidikan Islam saat ini memiliki peluang yang besar dan strategis untuk terus berkembang karena memiliki landasan dan konsepsi yang jelas dan sangat relevan dengan kebutuhaan dan tantangan yang dihadapi masyarakat Indonesia umumnya dan masyarakat Islam umumnya saat ini. Sebagaimana dimaklumi bahwa kurikulum memiliki fungsi holistik dalam dunia pendidikan ia memiliki peran dan fungsi sebagai wahana dan media konservasi, internalisasi, kristalisasi, dan transpormasi ilmu pengetahuan, tekhnologi, seni dan nilai-nilai kehidupan umat manusia. Oleh karena itu muatan kurikulum pengembangan pendidikan islam berwawasan kebangasaan perlu menampilkan ajaran ajaran islam 
berwawasan kebangsaan yang mengajarkan arti dan makna; cinta pada tanah air, menjunjung perdamaian, bekerjasama secara produktif, menghargai perbedaan, menjaga persatuan dan kesatuan dengan tujuan dan menitikberatkan pada pemahaman dan upaya untuk bisa hidup dalam konteks perbedaan paham agama dan budaya, baik secara individual maupun kelompok yang tidak terjebak pada frimordialisme dan eksklusivisme kelompok agama dan budaya yang sempit sehingga sikap-sikap kebangsaan tersebut dapat ditumbuh kembangkan dalam diri generasi muda Indonesia melalui dimensi-dimensi pendidikan Islam, disinilah letak pentingnya pengembangan nilai-nilai kebangsaan dalam kurikulum pendidikan Islam[.]

\section{REFERENSI}

Ade Imelda, dan Frimayanti. "IMPLEMENTASI PENDIDIKAN NILAI DALAM PENDIDIKAN AGAMA ISLAM" 6 (November 2015).

Konsep dan Model Pengembangan Kurikulum. Arifin Zainal vol. Bandung: Remaja Karya, 2011.

Asghar Ali Enginer. "Devolusi Negara Islam, Teerj. Imam Muttaqin." Yogyakarta: Pustaka Pelajar, 2000.

David L Sill (ed). "new York international Encyclopedia of the social scence the Mee Millon," 1972.

Departemen Pendidikan Nasiaonal, Panduan Pelaksanaan, Hal. 8-9 (t.t.).

Departemen Pendidikan Nasional Doirektorat Jenderal Pendidikan Dasar dan Menengah DirektoratPembinaan Menengah. Pertama Panduan Pelaksanaan Pendidikan Berwawasan Kebangsaan, 2009.

Departemen Pendidikan Nasional, Panduan Pelaksanaan, t.t.

"Encyclopedia britanica the university (cicagi:851).," t.t.

Hasan Langgulung. Asas-Asas Pendidikan Islam. Jakarta: Pustaka AlHusna, 1963.

M. Ainul Yaqin. , Pendidikan Multicultural (Cross-Cultural Understanding Untuk Demokrasi danKeadilan). Yogyakarta: Pilar Media, 2005. 
M. Amin Abdulah. Pendidikan Agama Era Multikultural Religius. (Jakarta: Psap Muhammaddiyah, 2005.

Muchith, M Saekan. "Problem Keilmuan Pendidikan Agama Islam." JURNAL PENELITIAN 9, no. 2 (1 Agustus 2015): 389. https:// doi. org/10.21043/jupe.v9i2.1327.

Muhaimin. Arah Baru Pengembangan Pendidikan Islam. Bandung: Tarsito, 2003.

Muhammad Fathurahman. "Pendidikan Islam Mesti Cultural, Mengutif dari Artikel Nur Effendi Pendidik 06@ Yahoo.Co.Id," t.t.

Mujibur Rahman. "Problamatik Kurikulum Pendidikan Islam" VIII (Januari 2015): 3.

Nilawati Tajuddin. Pendidikan Moral Anak Usia Dini Dalam Pandangan Nasikh Ulwan dan Kallbreg. lampung: LP2M UIN Lampung, 2017.

"Samsul Bahri Pengembangan Kurikulum Dasar dan Tujuannya Jurnal Islam Putura.," t.t.

Scott Lash Dan Mike Featherstone (Ed.),. Recognition And Difference: Politics, Identity, Multiculture. Londen: Sage Publication, 2002.

Slueek E.T.A. "Morl Dicriminatif Instrument For The Identification Of Polential Deliguments Al Sehool Entrane Journal of Criminal Law" 51 (1966): 27,30,50.

Stoddard, L. . dunia BMM islam. Jakarta: gunung agung, 1964.

Subhan, Fauti. "Memahami Pendidikan Islam." Nadwa 7, no. 1 (20 April 2013): 141. https:// doi.org/10.21580/nw.2013.7.1.547.

Syafe'I, Imam. “TUJUAN PENDIDIKAN ISLAM.” Jurnal Pendidikan Islam 6 (2015): 16.

Undang-Undamg System Pendidikan Nasional, Cet. III. Yogyakarta: Pustaka Pelajar, 2009. 